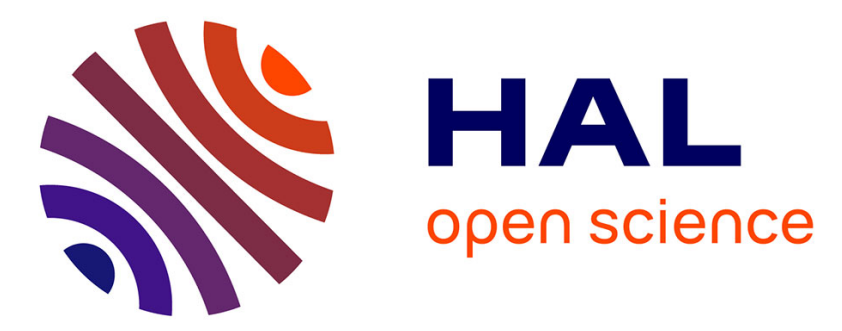

\title{
Clinical, imaging, and histological presentations and outcomes of stroke related to sarcoidosis
}

Vincent Jachiet, Raphael Lhote, Pierre Rufat, Micheline Pha, Julien Haroche, Sophie Crozier, Corinne Dupel-Potier, Dimitri Psimaras, Zahir Amoura, Fleur Cohen Aubart

\section{To cite this version:}

Vincent Jachiet, Raphael Lhote, Pierre Rufat, Micheline Pha, Julien Haroche, et al.. Clinical, imaging, and histological presentations and outcomes of stroke related to sarcoidosis. Journal of Neurology, 2018, 265 (10), pp.2333-2341. 10.1007/s00415-018-9001-x . hal-01972154

\section{HAL Id: hal-01972154 \\ https://hal.sorbonne-universite.fr/hal-01972154}

Submitted on 8 Jan 2019

HAL is a multi-disciplinary open access archive for the deposit and dissemination of scientific research documents, whether they are published or not. The documents may come from teaching and research institutions in France or abroad, or from public or private research centers.
L'archive ouverte pluridisciplinaire $\mathbf{H A L}$, est destinée au dépôt et à la diffusion de documents scientifiques de niveau recherche, publiés ou non, émanant des établissements d'enseignement et de recherche français ou étrangers, des laboratoires publics ou privés. 
Clinical, imaging, and histological presentations and outcomes of stroke related to sarcoidosis

Running title: Stroke in sarcoidosis

Vincent JACHIET ${ }^{1}$, MD, Raphael LHOTE ${ }^{1}$, MD, Pierre RUFAT ${ }^{2}$, MD, Micheline PHA ${ }^{1}$, MD, Julien HAROCHE${ }^{1}$, MD, PhD, Sophie CROZIER ${ }^{3}$, MD, Corinne DUPEL-POTIER ${ }^{4}$, MD, Dimitri PSIMARAS $^{5}, \mathrm{MD}, \quad$ Zah ir AM OURA 1 , MD, MSc and Fleur COHEN AUBART ${ }^{1}, \mathrm{MD}, \mathrm{PhD}$

(1) Sorbonne Université, Faculté de Médecine, Assistance Publique Hôpitaux de Paris, Hôpital de la Pitié-Salpêtrière, Service de Médecine Interne 2, Centre National de Référence Maladies Systémiques Rares, PARIS-75013, France

(2) Assistance Publique Hôpitaux de Paris, Hôpital de la Pitié-Salpêtrière, Département Biostatistiques, PARIS-75013, France

(3) Assistance Publique Hôpitaux de Paris, Hôpital de la Pitié-Salpêtrière, Service de Neurologie Vasculaire, PARIS-75013, France

(4) Hôpital de Pontoise, Service de Neurologie, PONTOISE-95000, France

(5) Assistance Publique Hôpitaux de Paris, Hôpital de la Pitié-Salpêtrière, Service de Neurologie, PARIS-75013, France

Correspondence to Dr. Fleur COHEN-AUBART, Service de Médecine Interne 2, Institut e3m, Hôpital de la Pitié-Salpêtrière, 47-83 Boulevard de l’hôpital, 75651 PARIS CEDEX 13, France Email fleur.cohen@aphp.fr

Phone +33142178242

Fax +33142165804 
Word count in abstract: 230

Word count in full text: 2529

Character count in title including spaces: 87

Number of tables: 4

Number of figures: 1

Number of references: 34

Key words: sarcoidosis, stroke, brain ischemia, intracranial hemorrhages, cerebral venous thrombosis

The authors declare no conflicts of interest and no disclosures relevant to the manuscript.

This work was not supported by any funding.

V.J., P.R., Z.A. and F.C.A. were involved in the study design

All the authors contributed to analysis and interpretation of the data.

V.J., R.L., C.D.P., S.C. and F.C.A. contributed to the acquisition of data.

V.J, R.L. and F.C.A. conducted the statistical analysis.

Z.A. and F.C.A. coordinated the study.

All the authors contributed to drafting/revising the manuscript for content.

All the authors approved the final submitted version. 


\begin{abstract}
Objectives: Clinical involvement of the nervous system is uncommon during sarcoidosis. Cerebrovascular events are rarely reported during sarcoidosis and may be confused with primary angiitis of the central nervous system. The characteristics and outcomes of cerebrovascular events during sarcoidosis have not been well-evaluated.
\end{abstract}

Patients and methods: We conducted a retrospective case-series in our institution with an updated review of the literature from 1962 to 2017 to characterize the clinical presentation, imaging, histology and outcomes of stroke that were thought to be causally related to sarcoidosis.

Results: Fifty-one patients (31 men, median age at stroke diagnosis of 41 years) receiving a diagnosis of stroke and sarcoidosis, including 8 new cases from our institution and 43 from the literature review, were included. Stroke was the first manifestation of sarcoidosis in $64 \%$. The stroke was ischemic in 69\% and hemorrhagic in 31\%. A total of 31\% experienced a transient ischemic attack before ischemic stroke. A total of $36 \%$ of patients had multiple infarcts or hemorrhages. The median number of cardiovascular risk factors was 0 . Concerning histological presentation, vascular or perivascular involvement was present in all cases. After a median follow-up of 12 months (after stroke), up to 50\% of patients had developed a permanent neurological impairment, $16 \%$ had a recurrence of stroke, and $23 \%$ died. Conclusions: Cerebrovascular events may be the first manifestation of neurosarcoidosis, and have a prognosis impact in such patients, leading to death and permanent neurological impairment. 


\section{Introduction}

Sarcoidosis is a multi-systemic granulomatous disease of unknown cause characterized by infiltration of the tissues by non-caseating granulomas. It affects various organs, including the lungs in $90 \%$ of the patients. Sarcoidosis may remit spontaneously, although it can also be chronic or progressive in up to $25 \%$ of patients [32]. Clinical involvement of the central nervous system (CNS) occurs in $5-10 \%$ of cases $[9,10,15,17,18,29]$, and subclinical CNS involvement has been observed in up to $27 \%$ of sarcoidosis patients in autopsy studies [14, 24]. Sarcoidosis may affect virtually any part of the central or peripheral nervous system (PNS). Clinical manifestations of neurosarcoidosis are variable but most frequently appear as cranial neuropathy, focal or multifocal encephalopathy, and rarely, intracranial hypertension [6]. Despite the evidence for granulomatous involvement of the vessels in histological studies, vasculitis is not a classical feature of sarcoidosis. Stroke related to neurosarcoid vasculitis is rare and limited to case reports or small series $[2,4,7,8,11,19,21,23]$. However, in a recent study, the relative risk of cerebrovascular comorbidity in 345 patients with sarcoidosis from 1976 to 2013 compared with 345 individuals without sarcoidosis was 10.06 (95\% confidence interval (CI) 1.29-78.67) in the first 5 years after diagnosis and 1.87 (1.00-3.50) after 5 years, suggesting a specific mechanism of stroke during sarcoidosis [30].

However, the characteristics and outcomes of cerebrovascular events during sarcoidosis have not been well-evaluated. We therefore conducted a retrospective case-series with an updated review of the literature to characterize the clinical and biological, imaging and histology presentations and to evaluate the outcomes of cerebrovascular events related to sarcoidosis.

\section{Patients and Methods}

\section{Patient selection}

We performed a retrospective study in an internal medicine Department and stroke unit of a French University hospital. Patients were identified through the computerized local database 
of hospitalized patients (Programme de Médicalisation des Systèmes d'Information, PMSI) between 2005 and 2017 using the codes of International Statistical Classification of Diseases and Related Health Problems (ICD-10) for "sarcoidosis" (i.e., D86) and "ischemic or hemorrhagic stroke" (i.e., G45 and I60, I61, I62, I63 or I64), which were likely to appear as the principal of associated codes for the hospital stay. All forms of cerebrovascular events were considered, including transient ischemic attacks (TIA), hemorrhagic or ischemic strokes and cerebral venous thrombosis (CVT). Medical records were reviewed, and patients were included if they received a diagnosis of sarcoidosis according to the American Thoracic Society (ATS) / World Association on Sarcoidosis and other Granulomatous diseases (WASOG) recommendations [1], a CNS localization corresponding to a "definite" or "probable" neurosarcoidosis ("definite" when non-caseating granuloma were found in the neurologic tissue, "probable" when non-caseating granuloma were found elsewhere) [34], and had experienced a cerebrovascular event. The patients were excluded if they were not screened for cardiac and cerebral large vessels diseases or if the cerebrovascular event was related to a cardioembolic event (e.g., atrial fibrillation) or atherosclerotic lesions. Finally, 2 physicians (V.J. and F.C.-A.) independently reviewed the medical charts of the remaining patients who were excluded if the stroke did not seem related to sarcoidosis and if the stroke occurred before the first clinical manifestation of sarcoidosis.

\section{Literature review}

We conducted a systematic search through the National Library of Medicine's MEDLINE database and Web of Science Medline library for relevant literature using the keywords "sarcoidosis" OR "neurosarcoidosis" OR "granulomatosis" OR "granuloma” OR "sarcoid" AND "stroke" OR "brain ischemia" OR "intracranial hemorrhages” OR “cerebral venous thrombosis". All articles published in English or French between 1962 and 2017 were reviewed. Three hundred and six references were screened, and the references of selected 
articles were reviewed for additional case reports. The articles were included if the patients met the criteria described above. Patients for whom another cause of stroke was more probable were excluded. Thus we included patients for whom stroke was thought to be causally related to sarcoidosis. The demographic and clinical characteristics and biological, imaging and histological presentations were collected, as well as the treatments received and outcomes.

\section{Data collection}

The characteristics of the patients were obtained through medical records. The following data were collected: demographic characteristics, delay between the onset of sarcoidosis and cerebrovascular event, localizations of sarcoidosis, blood test results (including serum Angiotensin-Converting Enzyme (ACE)), cerebrospinal fluid (CSF) and imaging data, histological results, treatments and outcomes. Stroke characteristics were recorded, including clinical features and cerebral MRI findings (involved territory, multiple localizations or cerebral vasculitis).

\section{Statistical analyses}

Data are presented as the median (range) for continuous variables and number (\%) for qualitative variables. When data were lacking, the percentage was calculated using the available data.

\section{Results}

\section{Patient characteristics}

We screened 17 patients from the PMSI, and 8 patients were included. Nine patients were excluded because they did not meet the inclusion criteria for the following reasons: other diagnosis than sarcoidosis $(n=5)$, no histological documentation $(n=2)$, no stroke $(n=1)$ and 
embolic stroke (n=1). From the 306 articles in the literature, 34 were included, corresponding to 43 cases. A total of 272 articles were excluded because they did not meet the inclusion criteria for the following reasons: diagnosis other than sarcoidosis $(n=150)$, no stroke $(n=92)$, no histological documentation $(n=16)$, language other than English or French $(n=6)$, and no full text available ( $\mathrm{n}=8)$. Thus, we analyzed 51 cases, including 8 new cases.

The baseline characteristics of the patients are detailed in Table 1. Patients were predominantly men $(n=31 / 46,67 \%$; in 5 cases, the gender was not specified) with a median age of 41 [range 21-73] at stroke diagnosis. Thirty-six of 39 patients (92\%) had an extraneurologic involvement of sarcoidosis. The main manifestations of sarcoidosis were mediastinal lymph nodes or lungs ( $n=35 / 39,90 \%)$, eyes $(n=8 / 39,21 \%)$, skin $(n=7 / 39,18 \%)$, ear-nose-throat $(n=7 / 39,18 \%)$, liver or spleen $(n=5 / 39,13 \%)$, extra-thoracic lymph node involvement $(n=3 / 39,8 \%)$ or other $(n=5 / 39,13 \%)$. The median number of organs involved was $1[0-6]$.

Twenty-one of 34 patients (62\%) had at least one laboratory test abnormality, mostly serum ACE increased $(n=15 / 34,44 \%)$.

All the patients $(n=51 / 51,100 \%)$ had a histopathological confirmation of sarcoidosis as required in the inclusion criteria. For 8 patients, data of the autopsy were available. Eighteen patients (35\%) were classified as having definite neurosarcoidosis and $33(65 \%)$ as probable neurosarcoidosis. Three patients (8\%) had an isolated neurosarcoidosis, without extraneurological involvement. The most common clinical manifestations were encephalopathy ( $n=18 / 41,44 \%$ ) (focal sensory or motor defects, ataxia, cognitive or behavioral change, seizures or neuroendocrine dysfunction), headache or hydrocephalus $(n=14 / 41,34 \%)$ and cranial neuropathy $(\mathrm{n}=8 / 41,20 \%)$.

A lumbar puncture was performed in 30 patients (59\%) and demonstrated a pleocytosis and/or elevated protein level in 27 cases. CSF total protein was elevated in 24 of 30 patients (80\%), pleocytosis was found in 23 of 30 patients (77\%), and CSF oligoclonal bands with 
elevated IgG-index (increased synthesis rate in the CSF) was observed in 8 of 30 patients $(27 \%)$

Cranial MRI showed abnormalities in 29 of 32 evaluated patients (91\%), mostly consisting of white matter hyperintense lesions in T2-weighted sequences ( $n=22 / 32,69 \%)$, leptomeningeal thickening or enhancement $(n=14 / 32,44 \%)$ and hydrocephalus $(n=7 / 32$, $22 \%)$. Vasculitis was found in 18 of 32 cases (55\%) on magnetic resonance angiography or cerebral arteriography (Figure 1).

Among the patients with ischemic stroke, 1 patient had low titers of anti- $\beta 2$ glycoprotein I antibodies (in our series), 1 had anticardiolipin antibodies [33], and 1 with CVT was heterozygous for the factor V Leiden mutation [28].

\section{Characteristics of the cerebrovascular events}

The characteristics of the cerebrovascular events are detailed in the Table 2 . The median number of cardiovascular risk factors was 0 (mean 0.6). Clinical manifestations of stroke were hemiparesis $(n=34 / 45,76 \%)$, aphasia $(n=14 / 45,31 \%)$, dysarthria $(n=10 / 45,22 \%)$, seizure $(n=8 / 45,18 \%)$, sensory deficit $(n=7 / 45,16 \%)$ and cerebellar ataxia $(n=7 / 45,16 \%)$.

The stroke was ischemic in 35 cases (69\%) and hemorrhagic in 18 (31\%). Among hemorrhagic strokes, 2 patients had hemorrhagic infarcts linked to CVT, and one patient experienced an ischemic stroke with secondary hemorrhagic transformation. Eleven of 35 patients (31\%) experienced transient ischemic attack before ischemic stroke. CVT was noted in 2 of 51 cases $(4 \%)$.

In 23 cases out of 45 (51\%), the stroke was located in the carotid system only, whereas 12 of 45 events (27\%) were located in the vertebrobasilar system only, and 10 of $45(22 \%)$ involved both carotid and vertebrobasilar systems. Strokes occurred more frequently in the middle cerebral artery territory $(n=25 / 41,61 \%)$ and less frequently in the anterior, cerebellar or posterior cerebral arteries (respectively in 39\%, 37\% and 29\% of cases). Sixteen 
patients (36\%) had multiple infarcts or hemorrhages.

Stroke was the first manifestation of sarcoidosis in 29 of 45 patients (64\%). Cerebrovascular events occurred in 16 of 45 patients (36\%) after the diagnosis of sarcoidosis with a median delay of 39 months $(0.5-360)$.

\section{Histological presentations}

The histological results of a CNS biopsy $(n=2)$ or autopsy $(n=7)$ were available corresponding to 1 patient of our series and 8 from literature review. These results are detailed in Table 3 . Histological granulomatous meningitis was seen in 8 of 8 cases $(100 \%)$ and parenchymal granulomas in 7 of 8 cases (88\%). A vascular or perivascular involvement was seen in $100 \%$ of cases, consisting of perivascular granulomas in 6 of 9 patients (67\%), granulomatous vasculitis in 7 of 9 patients (78\%) or medium/small vessels vasculitis with fibrinoid necrosis in 4 of 9 patients (44\%). Arteries and veins were involved in 6 of 8 patients (75\%) and 6 of 7 patients (86\%), respectively. Evidence for small-vessel stenosis or occlusion was found in 3 of 6 patients (50\%). A microscopic infarction or hemorrhage was seen in 6 of 7 patients (86\%) each.

\section{Treatments and outcomes}

The treatments administered for neurosarcoidosis are presented in Table 4. Before experiencing the stroke, the patients had been treated with corticosteroids $(n=8 / 41,20 \%)$ or immunosuppressive drugs ( $\mathrm{n}=2 / 41,5 \%)$. After the stroke, 33 of 39 patients (85\%) were treated with corticosteroids, and 14 patients (36\%) received an immunosuppressive drug (among methotrexate (MTX), cyclophosphamide (CYC), azathioprine (AZA), anti-TNF, intravenous immunoglobulins (IVIG), rituximab (RTX) or mycophenolate mofetil (MMF)). The median follow-up after a stroke was 12 months (ranging from 1 to 240 months). It is worth noting that at the end of follow-up, almost half of the patients ( $n=20 / 43,47 \%$ ) had 
developed a neurological impairment, whereas almost one-third of them $(n=13 / 43,30 \%)$ had recovered without sequelae. Seven of 43 patients (16\%) had a recurrence of stroke and, in most cases, two relapses or more $(n=5 / 7)$. Ten patients died $(23 \%)$; among them, seven deaths were linked to neurosarcoidosis and cerebrovascular events.

\section{Discussion}

Despite numerous pathological studies showing granulomatous involvement of small vessels in sarcoidosis, clinical signs of "vasculitis", in particular stroke events, related to sarcoidosis are rare. In this study, we found 43 cases of sarcoidosis-related strokes in the literature and 8 new cases in our center, which is a tertiary center highly specialized in sarcoidosis care. The main results of this study can be summarized as follows: i) cerebrovascular events had a variable presentation, ranging from ischemic transient or permanent strokes with large or small vessels to hemorrhagic stroke or central venous thrombosis; ii) stroke was the first sign of sarcoidosis in up to $40 \%$ of cases; iii) most of the patients had several signs of disease activity at the time of stroke, including signs of neurological involvement, and this provides an argument for a direct role of sarcoidosis in the occurrence of stroke; and iv) half of the patients had neurological sequelae after stroke, and 23\% died, which is an important note for clinicians. A key feature of our study was that 2 independent physicians reviewed all the cases, and we excluded those in which the link between stroke and sarcoidosis was not certain. Thus we described only the cases that were thought to be causally related to sarcoidosis.

The discrepancy between the frequency of pathological involvement of vessels and clinical involvement of vessels in sarcoidosis is striking. Histological studies (from brain biopsy or autopsy) of sarcoidosis have consistently shown evidence of vascular involvement $[3,5,13$, 20, 22, 25-27]. These studies characteristically showed granulomatous meningitis predominantly involving the basal meninges, with frequent parenchymal and occasional 
ependymal involvement [13]. The granuloma tend to invade the cerebral parenchyma along the Virchow-Robin spaces and are distributed around the vessels [22]. Granuloma preferentially spread around small- to medium-sized arteries (i.e., vessels with caliber of the perforating arteries), which explains why cerebral arteriography or magnetic resonance angiography are typically normal in neurosarcoidosis [13]. Larger vessel involvement is exceptional in the literature and may correspond to direct compression of marge vessels by granulomatous masses [7]. The granuloma are described in most cases in the adventitia and less frequently in the media or intima, leading to disruption of the media and internal elastic lamina $[20,25]$. Thus, the mechanism of cerebrovascular events is supposed to be granulomatous invasion of the blood vessel walls and vascular compression by granulomas rather than the inflammation of the cerebral vasculature. However, few cases of granulomatous angiitis with fibrinoid necrosis in the vessels walls have been described, resulting in obliteration of the arterial lumen and intense leukocyte infiltration similar to medium or small vessels vasculitis. Moreover, we found that granulomas involved both arteries and veins. It is worth noting that sarcoidosis vasculitis more commonly results in a slowly progressive encephalopathy rather than an ischemic infarct as demonstrated by Brown in a neuropathologic review: 14 of 19 cases with histologically proven vasculitic changes were clinically manifested as encephalopathy, whereas only five had presented with a stroke or transient ischemic attack [2].

Another important finding is that within most cases in our studies, stroke events were associated with systemic involvement of sarcoidosis with evidence for clinical manifestation of neurosarcoidosis, inflammatory CSF or abnormal brain MRI. Thus, we can conclude that cerebrovascular events are a true manifestation of neurosarcoidosis due to vasculopathy rather than vasculitis, although this feature has also been rarely described. However, other mechanisms of cerebrovascular events may occur: in the literature, 1 had anticardiolipin antibodies [33], and 1 was heterozygous for the factor V Leiden mutation [28]. 
Venous thrombosis risk is increased during sarcoidosis and may play a role in the occurrence of CVT [31].

We found that cerebrovascular events during sarcoidosis were associated with a high mortality rate (23\%). According to a recent meta-analysis, the mortality rate during neurosarcoidosis was 5\% (42 of 826 patients; 95\% CI 4-7\%) [12,16]. Thus, we can suppose that stroke is associated with increased mortality during neurosarcoidosis. In a multiplecause-of-death analysis of mortality related to sarcoidosis in France, strokes were associated with death in women older than 85 years. The death certificates did not allow for conclusions regarding whether strokes were directly linked to sarcoidosis.

Our study has several limitations: first, data from cases reported in the literature are lacking. In our center, the cases were found through the medical codes in the PMSI, and we can suspect that all the patients were not identified. In most of the cases, histological documentation of granuloma was not obtained in the brain at the time of stroke. Thus the link between sarcoidosis and the stroke is not always absolutely certain. However, in most of the cases, the sarcoidosis was highly active at the time of stroke and no other cause was identified. We cannot exclude that other factors than sarcoidosis, such as corticosteroids, may have participated in the stroke occurrence.

\section{Conclusion}

Cerebrovascular events related to neurosarcoidosis have a variable presentation, consisting of ischemic or hemorrhagic stroke, transient ischemic attack or CVT. The causes are heterogeneous, ranging from direct compression from granulomatous masses to medium or small vessel involvement to venous thrombosis. However, the main pathophysiological mechanism seems to be a granulomatous invasion of the blood vessel walls rather than inflammation of the cerebral vessels. Cerebrovascular events may be the first manifestation of 
neurosarcoidosis, and clinicians should attend to features that can guide the sarcoidosis diagnosis, including young age, leptomeningeal involvement, and evidence of extraneurological involvement. In sarcoidosis, stroke is associated with a high risk of permanent neurological impairment (up to $50 \%$ of patients) and a high mortality rate, as $23 \%$ of patients died. Relapses are common and require effective and likely prolonged courses of treatment. 
Table 1. Patient characteristics: demographic, clinical, and biological presentations and imaging data (our series, $n=8$; literature review, $n=43$ ).

\begin{tabular}{|c|c|c|c|}
\hline & All $(n=51)$ & Cases $(n=8)$ & $\begin{array}{l}\text { Review } \\
(\mathrm{n}=43)\end{array}$ \\
\hline $\begin{array}{l}\text { Age, median at diagnosis (years } \\
\text { [range]) }\end{array}$ & $41.0[21-73]$ & $43.5[26-60]$ & $39.5[21-73]$ \\
\hline Sex, female & $15 / 46(33 \%)$ & $4 / 8$ & $11 / 38$ \\
\hline Isolated neurosarcoidosis & $3 / 39(8 \%)$ & $0 / 8$ & $3 / 31$ \\
\hline Extra-neurologic involvement & $36 / 39(92 \%)$ & $8 / 8$ & $28 / 31$ \\
\hline $\begin{array}{l}\text { Number of non-nervous system } \\
\text { organs involved [mean, range]) }\end{array}$ & $1.8[0-6]$ & $2.25[1-6]$ & $1.7[0-5]$ \\
\hline $\begin{array}{l}\text { Mediastinal lymph node } \\
\text { and/or lung }\end{array}$ & $36 / 39(92 \%)$ & $8 / 8$ & $26 / 31$ \\
\hline - Eye & $8 / 39(21 \%)$ & $2 / 8$ & $6 / 31$ \\
\hline - Skin & $7 / 39(18 \%)$ & $1 / 8$ & $6 / 31$ \\
\hline - Ear Nose Throat & $7 / 39(18 \%)$ & $3 / 8$ & $4 / 31$ \\
\hline - Liver and/or spleen & $5 / 39(13 \%)$ & $2 / 8$ & $3 / 31$ \\
\hline - Lymph nodes (extra-thoracic) & $3 / 39(8 \%)$ & $0 / 8$ & $3 / 31$ \\
\hline - Bones / arthritis & $1 / 39(3 \%)$ & $1 / 8$ & $0 / 31$ \\
\hline - Heart & $1 / 39(3 \%)$ & $1 / 8$ & $0 / 31$ \\
\hline - Kidney & $2 / 39(3 \%)$ & $0 / 8$ & $2 / 31$ \\
\hline - Pancreas & $1 / 39(3 \%)$ & $0 / 8$ & $1 / 31$ \\
\hline \multicolumn{4}{|l|}{ Laboratory tests at diagnosis } \\
\hline$-\quad \geq 1$ abnormality & $21 / 34(62 \%)$ & $8 / 8$ & $13 / 26$ \\
\hline - Serum ACE increased & $15 / 34(44 \%)$ & $5 / 8$ & $10 / 26$ \\
\hline - Hypergammaglobulinemia & $6 / 34(18 \%)$ & $4 / 8$ & $2 / 26$ \\
\hline - Serum calcium increased & $3 / 34(9 \%)$ & $2 / 8$ & $1 / 26$ \\
\hline - Cholestasis & $5 / 34(15 \%)$ & $4 / 8$ & $1 / 26$ \\
\hline - Lymphopenia & $4 / 34(12 \%)$ & $1 / 8$ & $3 / 26$ \\
\hline - Tuberculin anergy & $3 / 34(9 \%)$ & $2 / 8$ & $1 / 26$ \\
\hline \multicolumn{4}{|l|}{ Diagnosis of neurosarcoidosis } \\
\hline $\begin{array}{l}\text { Histopathological } \\
\text { confirmation }\end{array}$ & $\begin{array}{c}51 / 51 \\
(100 \%)\end{array}$ & $8 / 8$ & $42 / 43$ \\
\hline - Definite neurosarcoidosis & $18 / 51(35 \%)$ & $1 / 8$ & $17 / 43$ \\
\hline - Probable neurosarcoidosis & $33 / 51(65 \%)$ & $7 / 8$ & $26 / 43$ \\
\hline \multicolumn{4}{|l|}{$\begin{array}{l}\text { Clinical manifestations of } \\
\text { neurosarcoidosis }\end{array}$} \\
\hline - None & 9/41 (22\%) & $3 / 7$ & $6 / 34$ \\
\hline $\begin{array}{l}\quad \geq 1 \text { abnormality suggesting } \\
\text { NS }\end{array}$ & $32 / 41(78 \%)$ & $4 / 7$ & $28 / 34$ \\
\hline - Cranial neuropathy & $8 / 41(20 \%)$ & $2 / 7$ & $6 / 34$ \\
\hline - Headache/hydrocephalus & $14 / 41(34 \%)$ & $1 / 7$ & $13 / 34$ \\
\hline $\begin{array}{l}\text { - Encephalopathy (at least one } \\
\text { among) }\end{array}$ & $18 / 41(44 \%)$ & $3 / 7$ & $15 / 34$ \\
\hline $\begin{array}{l}\text { - Focal sensory or motor } \\
\text { defects }\end{array}$ & $6 / 41(15 \%)$ & $2 / 7$ & $4 / 34$ \\
\hline - Ataxia & $3 / 41$ & $0 / 7$ & $3 / 34$ \\
\hline - Cognitive/behavioral & $5 / 41$ & $2 / 7$ & $3 / 34$ \\
\hline
\end{tabular}


change

- Seizures

- Neuroendocrine dysfunction

- Spinal cord/Myelopathy

- Peripheral neuropathy Myopathy

Cerebrospinal fluid analysis

- Lumbar puncture performed

- CSF inflammation

- Pleocytosis

- Elevated protein

- Elevated IgG index or presence of oligoclonal bands

$$
4 / 41
$$

$2 / 7$

$2 / 34$

$2 / 41$

$0 / 7$

$2 / 34$

$3 / 41(7 \%)$

$0 / 7$

$3 / 34$

$1 / 41(2 \%)$

$0 / 7$

$1 / 34$

$2 / 41(5 \%)$

$1 / 7$

$1 / 34$

$\begin{array}{ccc}\mathbf{3 0 / 5 1}(\mathbf{5 9 \% )} & \mathbf{6 / 8} & \mathbf{2 4 / 4 3} \\ \mathbf{2 7 / 3 0 ( 9 0 \% )} & \mathbf{5 / 6} & \mathbf{2 2 / 2 4} \\ 24 / 30(80 \%) & 5 / 6 & 19 / 24 \\ 25 / 30(83 \%) & 4 / 6 & 21 / 24\end{array}$

$8 / 30(27 \%)$

$2 / 6$

$6 / 24$

\begin{tabular}{|c|c|c|c|c|}
\hline \multicolumn{5}{|c|}{ Imaging data } \\
\hline \multirow{2}{*}{-} & \multirow{2}{*}{$\begin{array}{l}\text { MRI performed/available } \\
\geq 1 \text { abnormality suggesting } \\
\text { NS }\end{array}$} & $32 / 51(63 \%)$ & $6 / 8$ & $26 / 43$ \\
\hline & & $29 / 32(91 \%)$ & $6 / 6$ & $23 / 26$ \\
\hline \multirow{2}{*}{\multicolumn{2}{|c|}{$\begin{array}{l}\text { - Leptomeningeal thickening or } \\
\text { enhancement } \\
\text { - White matter hyperintense } \\
\text { lesions in T2-weighted } \\
\text { sequences }\end{array}$}} & $14 / 32(44 \%)$ & $1 / 6$ & $13 / 26$ \\
\hline & & $22 / 32(69 \%)$ & $6 / 6$ & $16 / 26$ \\
\hline \multirow{3}{*}{\multicolumn{2}{|c|}{$\begin{array}{ll}\text { - } & \text { Hydrocephalus } \\
\text { - } & \text { Focal mass lesion } \\
\text { - } & \text { Enhancement of } \\
& \text { hypothalamic-pituitary } \\
\text { structures }\end{array}$}} & $7 / 32(22 \%)$ & $1 / 6$ & $6 / 26$ \\
\hline & & $3 / 32(9 \%)$ & $0 / 6$ & $3 / 26$ \\
\hline & & $1 / 32(3 \%)$ & $1 / 6$ & $0 / 26$ \\
\hline- & $\begin{array}{l}\text { Intramedullary spinal cord } \\
\text { lesions }\end{array}$ & $1 / 32(3 \%)$ & $0 / 6$ & $1 / 26$ \\
\hline- & Vasculitis sarcoidosis & $18 / 32(55 \%)$ & $3 / 6$ & $15 / 26$ \\
\hline
\end{tabular}

MRI: Magnetic Resonance Imaging; CSF: Cerebrospinal Fluid; ACE: Angiotensin-Converting

Enzyme; NS: neurosarcoidosis 
Table 2. Characteristics of strokes in patients with sarcoidosis (our series, $n=8$; literature review, $n=43$ ).

\begin{tabular}{|c|c|c|c|}
\hline & All $(n=51)$ & Cases $(n=8)$ & $\begin{array}{l}\text { Review } \\
(n=43)\end{array}$ \\
\hline $\begin{array}{l}\text { Cardiovascular risk factors } \\
\text { (median, [range]) }\end{array}$ & $0[0-3]$ & $1[0-3]$ & $0[0-2]$ \\
\hline $\begin{array}{l}\text { Cardiovascular risk factors } \\
\text { (mean, [range]) }\end{array}$ & $0,6[0-3]$ & $1,4[0-3]$ & $0,4[0-2]$ \\
\hline - Current smoking & $8 / 38(21 \%)$ & $4 / 8$ & $4 / 30$ \\
\hline - Hypercholesterolemia & $1 / 38(3 \%)$ & $1 / 8$ & $0 / 30$ \\
\hline - Hypertension & $7 / 38(18 \%)$ & $4 / 8$ & $3 / 30$ \\
\hline - Diabetes mellitus & $2 / 38(5 \%)$ & $2 / 8$ & $0 / 30$ \\
\hline \multicolumn{4}{|l|}{ Clinical manifestations of stroke } \\
\hline - Aphasia & $14 / 45(31 \%)$ & $2 / 8$ & $12 / 37$ \\
\hline - Dysarthria & $10 / 45(22 \%)$ & $1 / 8$ & $9 / 37$ \\
\hline - Hemiparesis/hemiplegia & $34 / 45(76 \%)$ & $5 / 8$ & $29 / 37$ \\
\hline - Sensory deficit & $7 / 45(16 \%)$ & $1 / 8$ & $6 / 37$ \\
\hline - Cerebellar ataxia & $7 / 45(16 \%)$ & $0 / 8$ & $7 / 37$ \\
\hline - Visual loss & $4 / 45(9 \%)$ & $3 / 8$ & $1 / 37$ \\
\hline - Diplopia & $2 / 45(4 \%)$ & $0 / 8$ & $2 / 37$ \\
\hline - Seizure & $8 / 45(18 \%)$ & $1 / 8$ & $7 / 37$ \\
\hline - Cognitive/behavioral change & $4 / 45(9 \%)$ & $0 / 8$ & $4 / 37$ \\
\hline - Mental confusion & $4 / 45(9 \%)$ & $0 / 8$ & $4 / 37$ \\
\hline - Coma & $3 / 45(7 \%)$ & $0 / 8$ & $3 / 37$ \\
\hline \multicolumn{4}{|l|}{ Stroke subsets } \\
\hline \multirow{2}{*}{$\begin{array}{l}\text { - Ischemic stroke } \\
\text { - Transient ischemic } \\
\text { attack }\end{array}$} & $35 / 51(69 \%)$ & $7 / 8$ & $28 / 43$ \\
\hline & $11 / 35(31 \%)$ & $1 / 7$ & $10 / 28$ \\
\hline \multirow{3}{*}{$\begin{array}{l}\text { - Hemorrhagic stroke } \\
\text { - Hemorrhagic } \\
\text { transformation of } \\
\text { ischemic stroke } \\
\text { - Hemorrhagic } \\
\text { transformation of CVT }\end{array}$} & $18 / 51(35 \%)$ & $1 / 8$ & $17 / 43$ \\
\hline & $1 / 16$ & $0 / 1$ & $1 / 15$ \\
\hline & $2 / 18$ & $0 / 8$ & $2 / 43$ \\
\hline
\end{tabular}

Involved territory

- Area

- Carotid system only / Anterior only

$\begin{array}{lll}23 / 45(51 \%) & 4 / 8 & 19 / 37 \\ 12 / 45(27 \%) & 1 / 8 & 11 / 37 \\ 10 / 45(22 \%) & 3 / 8 & 7 / 37\end{array}$

/ both anterior and

$10 / 45(22 \%)$ posterior

- Artery

- Anterior cerebral artery

$16 / 41(39 \%)$

$2 / 8$

$14 / 33$

- Middle cerebral artery

$25 / 41(61 \%)$

$7 / 8$

$18 / 33$

- Posterior cerebral artery

$12 / 41(29 \%)$

$3 / 8$

$9 / 33$ 


\begin{tabular}{llcc}
\multicolumn{1}{c}{ Cerebellar artery } & $15 / 41(37 \%)$ & $2 / 8$ & $13 / 33$ \\
\hline $\begin{array}{l}\text { Multiple localizations } \\
\text { (infarcts/hematomas) }\end{array}$ & $\mathbf{1 6 / 4 4}(\mathbf{3 6 \% )}$ & $\mathbf{4} / \mathbf{8}$ & $\mathbf{1 2 / 3 6}$ \\
\hline $\begin{array}{l}\text { Diagnosis of sarcoidosis before } \\
\text { stroke }\end{array}$ & $\mathbf{1 6 / 4 5}(\mathbf{3 6 \% )}$ & $\mathbf{4 / 8}$ & $\mathbf{1 2 / 3 7}$ \\
\hline $\begin{array}{l}\text { No diagnosis of sarcoidosis } \\
\text { before stroke }\end{array}$ & $\mathbf{2 9 / 4 5}(\mathbf{6 4 \% )}$ & $\mathbf{4 / 8}$ & $\mathbf{2 5 / 3 7}$ \\
\hline $\begin{array}{l}\text { Median delay between first } \\
\begin{array}{l}\text { symptom of sarcoidosis } \\
\text { (diagnosed as such or not) and } \\
\text { stroke (months [range]) }\end{array}\end{array}$ & $\mathbf{3 9}[\mathbf{0 , 5 - 3 6 0 ]}$ & $\mathbf{4 8}[\mathbf{0 , 5 - 3 6 0 ]}$ & $\mathbf{3 6}[2-228]$ \\
\hline
\end{tabular}

$\mathrm{H}$ : hemorrhagic 
Table 3. Histological presentation (our series, $n=1$; literature review, $n=8$ ).

\begin{tabular}{lc}
\hline & $\mathbf{n = 9}$ \\
\hline Granulomatous meningitis & $8 / 8(100 \%)$ \\
Parenchymal granulomas & $7 / 8(88 \%)$ \\
Perivascular granulomas & $6 / 9(67 \%)$ \\
\hline Granulomatous vasculitis & $7 / 9(78 \%)$ \\
\hline Fibrinoid necrosis & $4 / 9(44 \%)$ \\
Arteries involved & $6 / 8(75 \%)$ \\
Veins involved & $6 / 7(86 \%)$ \\
Small-vessel stenosis or occlusion & $3 / 6(50 \%)$ \\
Microscopic infarction & $6 / 7(86 \%)$ \\
Microscopic hemorrhage & $6 / 7(86 \%)$ \\
\hline
\end{tabular}


Table 4. Treatments and outcomes in patients with neurosarcoidosis and stroke (our series, $\mathrm{n}=8$; literature review, $\mathrm{n}=43$ )

\begin{tabular}{|c|c|c|c|}
\hline & All $(n=51)$ & $\begin{array}{l}\text { Cases } \\
(n=8)\end{array}$ & $\begin{array}{l}\text { Review } \\
(\mathrm{n}=43)\end{array}$ \\
\hline Treatment before stroke & $8 / 41(20 \%)$ & $2 / 8$ & $6 / 33$ \\
\hline - Corticosteroids & $8 / 41(20 \%)$ & $2 / 8$ & $6 / 33$ \\
\hline - Immunosuppressor & $2 / 41(5 \%)$ & $2 / 8$ & $0 / 33$ \\
\hline - MTX & $1 / 2$ & $1 / 2$ & $0 / 33$ \\
\hline - $\mathrm{CYC}$ & $1 / 2$ & $1 / 2$ & $0 / 33$ \\
\hline \multicolumn{4}{|l|}{ Treatment after stroke } \\
\hline - Antiplatelet therapy & $15 / 39(38 \%)$ & $7 / 8$ & $8 / 31$ \\
\hline - Anticoagulant & $4 / 39(10 \%)$ & $0 / 8$ & $4 / 31$ \\
\hline - Corticosteroids & $33 / 39(85 \%)$ & $7 / 8$ & $26 / 31$ \\
\hline \multirow{8}{*}{$\begin{array}{l}\text { Immunosuppressive drug } \\
\text { - MTX } \\
\text { AZA }\end{array}$} & $14 / 39(36 \%)$ & $5 / 8$ & $9 / 31$ \\
\hline & $8 / 14$ & $4 / 5$ & $4 / 9$ \\
\hline & $3 / 14$ & $0 / 5$ & $3 / 9$ \\
\hline & $4 / 14$ & $1 / 5$ & $3 / 9$ \\
\hline & $2 / 14$ & $0 / 5$ & $2 / 9$ \\
\hline & $1 / 14$ & $0 / 5$ & $1 / 9$ \\
\hline & $1 / 14$ & $1 / 5$ & $0 / 9$ \\
\hline & $2 / 14$ & $2 / 5$ & $0 / 9$ \\
\hline \multirow[b]{3}{*}{ - Ventriculoperitoneal } & $5 / 39(13 \%)$ & $0 / 8$ & $5 / 31$ \\
\hline & $1 / 5$ & $0 / 8$ & $1 / 5$ \\
\hline & $4 / 5$ & $0 / 8$ & $4 / 5$ \\
\hline $\begin{array}{l}\text { Median follow up since/after } \\
\text { stroke (months [range]) }\end{array}$ & 12 [1-240] & $61[24-240]$ & $10[1-152]$ \\
\hline Outcomes & - & - & - \\
\hline - Recovery without sequelae & $13 / 43(30 \%)$ & $2 / 8$ & $11 / 35$ \\
\hline - Neurological impairment & $20 / 43(47 \%)$ & $6 / 8$ & $14 / 35$ \\
\hline - Stroke recurrence & $7 / 43(16 \%)$ & $2 / 8$ & $5 / 35$ \\
\hline - 1 relapse & $2 / 7$ & $0 / 2$ & $2 / 5$ \\
\hline - $\geq 2$ relapses & $5 / 7$ & $2 / 2$ & $3 / 5$ \\
\hline Death & $10 / 43(23 \%)$ & $0 / 8$ & $10 / 35$ \\
\hline
\end{tabular}

MTX: Methotrexate; CYC: Cyclophosphamide; AZA: Azathioprine; IVIG: Intravenous immunoglobulins; MMF: Mycophenolate Mofetil, RTX: Rituximab; Anti-TNF: Anti-Tumor Necrosis Factor-alpha

\section{Figure legend}

Figure 1. Magnetic Resonance angiography in a patient with sarcoidosis and stroke. Multiple narrowing in the 2 internal carotid arteries. 


\section{References}

1. (1999) Statement on sarcoidosis. Joint Statement of the American Thoracic Society (ATS), the European Respiratory Society (ERS) and the World Association of Sarcoidosis and Other Granulomatous Disorders (WASOG) adopted by the ATS Board of Directors and by the ERS Executive Committee, February 1999. American journal of respiratory and critical care medicine 160:736-755

2. Brown MM, Thompson AJ, Wedzicha JA, Swash M (1989) Sarcoidosis presenting with stroke. Stroke 20:400405

3. Camp WA, Frierson JG (1962) Sarcoidosis of the central nervous system. A case with postmortem studies. Arch Neurol 7:432-441

4. Campbell J, Kee R, Bhattacharya D, Flynn P, McCarron M, Fulton A (2015) Systemic Sarcoidosis Presenting with Headache and Stroke-Like Episodes. Case Reports Immunol 2015:619867

5. Caplan L, Corbett J, Goodwin J, Thomas C, Shenker D, Schatz N (1983) Neuro-ophthalmologic signs in the angiitic form of neurosarcoidosis. Neurology 33:1130-1135

6. Cohen Aubart F, Galanaud D, Haroche J, Psimaras D, Mathian A, Hie M, Le-Thi Huong Boutin D, Charlotte F, Maillart E, Maisonobe T, Amoura Z (2016) [Neurosarcoidosis: Diagnosis and therapeutic issues]. Rev Med Interne

7. $\quad$ Corse AM, Stern BJ (1990) Neurosarcoidosis and stroke. Stroke 21:152-153

8. Das SK, Sinha I, Kundu TN, Sanyal K, Santosh V, Shankar SK (1998) Two cases of neurosarcoidosis presenting as peripheral neuropathy and stroke in young. J Assoc Physicians India 46:479-481

9. Delaney P (1977) Neurologic manifestations in sarcoidosis: review of the literature, with a report of 23 cases. Annals of internal medicine 87:336-345

10. Ferriby D, de Seze J, Stojkovic T, Hachulla E, Wallaert B, Destee A, Hatron PY, Vermersch P (2001) Longterm follow-up of neurosarcoidosis. Neurology 57:927-929

11. Ferroir JP, Khalil A, Gounant V, Milleron B (2009) [Brain and medullar neurosarcoidosis, complicated by stroke with local vasculitis]. Rev Neurol (Paris) 165:596-600

12. Fritz D, van de Beek D, Brouwer MC (2016) Clinical features, treatment and outcome in neurosarcoidosis: systematic review and meta-analysis. BMC Neurol 16:220

13. Herring AB, Urich H (1969) Sarcoidosis of the central nervous system. J Neurol Sci 9:405-422

14. Iwai K, Tachibana T, Takemura T, Matsui Y, Kitaichi M, Kawabata Y (1993) Pathological studies on sarcoidosis autopsy. I. Epidemiological features of 320 cases in Japan. Acta Pathol Jpn 43:372-376

15. Joseph FG, Scolding NJ (2009) Neurosarcoidosis: a study of 30 new cases. Journal of neurology, neurosurgery, and psychiatry 80:297-304

16. Leonhard SE, Fritz D, Eftimov F, van der Kooi AJ, van de Beek D, Brouwer MC (2016) Neurosarcoidosis in a Tertiary Referral Center: A Cross-Sectional Cohort Study. Medicine 95:e3277

17. Lower EE, Broderick JP, Brott TG, Baughman RP (1997) Diagnosis and management of neurological sarcoidosis. Archives of internal medicine 157:1864-1868

18. Luke RA, Stern BJ, Krumholz A, Johns CJ (1987) Neurosarcoidosis: the long-term clinical course. Neurology 37:461-463

19. Macedo PJ, da Silveira VC, Ramos LT, Nobrega FR, Vasconcellos LF (2016) Isolated Central Nervous System Vasculitis as a Manifestation of Neurosarcoidosis. Journal of stroke and cerebrovascular diseases : the official journal of National Stroke Association 25:e89-92

20. Manz HJ (1983) Pathobiology of neurosarcoidosis and clinicopathologic correlation. Can J Neurol Sci 10:5055

21. Matsumoto K, Awata S, Matsuoka H, Nakamura S, Sato M (1998) Chronological changes in brain MRI, SPECT, and EEG in neurosarcoidosis with stroke-like episodes. Psychiatry Clin Neurosci 52:629-633

22. Meyer JS, Foley JM, Campagna-Pinto D (1953) Granulomatous angiitis of the meninges in sarcoidosis. AMA Arch Neurol Psychiatry 69:587-600

23. Navi BB, DeAngelis LM (2009) Sarcoidosis presenting as brainstem ischemic stroke. Neurology 72:10211022

24. Perry A, Vuitch F (1995) Causes of death in patients with sarcoidosis. A morphologic study of 38 autopsies with clinicopathologic correlations. Archives of pathology \& laboratory medicine 119:167-172

25. Reske-Nielsen E, Harmsen A (1962) Periangiitis and panangiitis as a manifestation of sarcoidosis of the brain: report of a case. J Nerv Ment Dis 135:399-412

26. Robert F (1962) Sarcoidosis of the central nervous system. Report of a case and review of the literature. Arch Neurol 7:442-449

27. Schonell ME, Gillespie WJ, Maloney AF (1968) Cerebral sarcoidosis. Br J Dis Chest 62:195-199

28. Selvi A, Diakou M, Giannopoulos S, Zikou AK, Argyropoulou MI, Kyritsis AP (2009) Cerebral venous thrombosis in a patient with sarcoidosis. Internal medicine 48:723-725

29. Stern BJ, Griffin DE, Luke RA, Krumholz A, Johns CJ (1987) Neurosarcoidosis: cerebrospinal fluid lymphocyte subpopulations. Neurology 37:878-881

30. Ungprasert P, Matteson EL, Crowson CS (2017) Increased Risk of Multimorbidity in Patients With 
Sarcoidosis: A Population-Based Cohort Study 1976 to 2013. Mayo Clin Proc 92:1791-1799

31. Ungprasert P, Srivali N, Wijarnpreecha K, Thongprayoon C (2015) Sarcoidosis and risk of venous thromboembolism: A systematic review and meta-analysis. Sarcoidosis Vasc Diffuse Lung Dis 32:182-187

32. Valeyre D, Prasse A, Nunes H, Uzunhan Y, Brillet PY, Muller-Quernheim J (2014) Sarcoidosis. Lancet 383:1155-1167

33. Vrethem M, Ernerudh J, Lindstrom F, Olsson JE (1992) Cerebral ischemia associated with anticardiolipin antibodies. Acta neurologica Scandinavica 85:412-417

34. Zajicek JP, Scolding NJ, Foster O, Rovaris M, Evanson J, Moseley IF, Scadding JW, Thompson EJ, Chamoun V, Miller DH, McDonald WI, Mitchell D (1999) Central nervous system sarcoidosis--diagnosis and management. QJM : monthly journal of the Association of Physicians 92:103-117 
Ho cut

$.1 \mathrm{~cm}$

4

VOI

DTOF/SPGR

30

$2.3 / \mathrm{Fr}$

$1 / 141.7 \mathrm{kHz}$

3BRAIN
DoB: Nov 151964 Ex:Sep 062016 $1.40 \times$ 